\title{
Cognitive reserve estimated with a life experience questionnaire outperforms education in predicting performance on MoCA: Italian normative data
}

\section{Sonia Montemurro ( $\nabla$ sn.montemurro@gmail.com )}

IRCCS San Camillo Hospital, Venice, Italy

\section{Roberta Daini}

Department of Psychology, University of Milano-Bicocca, Milan, Italy

\section{Chiara Tagliabue}

Center for Mind/Brain Sciences (CIMeC), University of Trento, Rovereto, Italy

\section{Sabrina Guzzetti}

Memory Clinic, Neurology Service, Humanitas San Pio X, Milan, Italy

\section{Giulia Gualco}

RSA Sant'Andrea, Monza, Italy

\section{Sara Mondini}

Department of Philosophy, Sociology, Education and Applied Psychology, FISPPA, University of Padova, Padua, Italy

\section{Giorgio Arcara}

IRCCS San Camillo Hospital, Venice, Italy

\section{Research Article}

Keywords: MoCA, cognitive reserve, normative data

Posted Date: October 28th, 2021

DOI: https://doi.org/10.21203/rs.3.rs-1016112/v2

License: @ (i) This work is licensed under a Creative Commons Attribution 4.0 International License. Read Full License

Version of Record: A version of this preprint was published at Current Psychology on April 15th, 2022. See the published version at https://doi.org/10.1007/s12144-022-03062-6. 


\section{Abstract}

Normative data of neuropsychological tests typically take into account the effect of demographic variables like age and education on performance. However, a broad literature has shown that, after the school age, other cognitively stimulating experiences (e.g., occupational attainment and a variety of leisure-time activities) may increase and build up cognitive reserve (CR), which is positively associated with better performance in neuropsychological tests.

With these premises, we investigated the predictive ability of education and a life-experience proxy of CR on a widely used cognitive screening, i.e., the Montreal Cognitive Assessment (MoCA).

Results show that including the more comprehensive life-experience CR proxy is better than considering only education in predicting expected cognitive performance. Based on the results of our analyses we provide normative data and cut-offs on 440 Italian individuals aged 50-90 years, by taking into account, for the first time for the Italian population, a CR index, together with demographic variables and Education, in the calculation of regression-based norms.

Accounting for life-experience CR proxies can improve the accuracy of normative data and allow a finer estimation of cognitive performance, which lead to a more tailored approach to patient assessment.

\section{Introduction}

In clinical neuropsychology, observed scores at neuropsychological tests alone cannot be easily interpreted to draw meaningful conclusions. For example, a performance of 25 at the MoCA test (Nasreddine et al., 2005) does not tell something specific per se, unless there is a way to interpret what this observed score may imply. There are many ways to obtain some reference scores, often called clinical cut-offs, that may help the interpretation of an observed performance (e.g., Crawford, Howell, \& Garthwaite, 1998; Crawford, Garthwaite, \& Porter, 2010). If the aim of the test is a classification of some specific clinical condition (e.g. having a Mild Cognitive Impairment vs having Alzheimer's Disease), specific methods, that are based on classification (as the Receiver Operating Characteristic, or ROC), allow to identify the optimal scores that help in classifying the belonging to one condition or to another (see Nasreddine et al., 2005). On the other side, if a cognitive test aims to identify the potential presence of specific or general cognitive impairment, cut-off scores are typically obtained from a reference sample of healthy people often referred to as "normative data" (Borland et al., 2017; Cesar, Yassuda, Porto, Brucki, \& Nitrini, 2019; Kopecek et al., 2017). Comparing a patient's performance with normative data makes possible to understand the potential meaning of an observed score: if that score is unlikely to be observed in healthy people, it could be a sign of cognitive worsening, or impairment.

To allow a meaningful comparison, normative data should be as much similar as possible to the patient, in order to accurately predict the expected performance and identify deviations that may be symptoms of cognitive impairment or decline. For this reason, normative data and cut-offs almost always take into account demographic variables, which are easy to collect in the context of a clinical setting, and are known to be associated with differences in cognitive performance (Strauss, Sherman, \& Spreen, 2006). In particular, the demographic variables that are typically considered in the development of normative data are age, sex, and education. 
Regarding age, it is widely known that physiological age-related brain changes can influence cognitive performance. Early studies about age-related effects on processing speed (Salthouse, 1993; Salthouse, 1996) have set the ground for further research demonstrating that aging does indeed affect a wide range of behavioral, cognitive, and neurological functions (Hohman et al., 2017; Jockwitz et al., 2019; Madden et al., 2020). In general, as age increases performance decreases (Proust-Lima, Amieva, Dartigues, \& Jacqmin-Gadda, 2007; Verhaeghen \& Salthouse, 1997). However, some neuropsychological test may show a different effect of age, that is a better performance as age increases (like in the case of vocabulary, whose size may increase along with the words encountered during life; Verhaeghen, 2003). Importantly, the effect of age could be linear, that is with cognitive performance that increases at a fixed rate with age, but also non-linear, that is with a linear relationship reaching a plateau and stabilizing, or having different slopes over age (Arcara \& Bambini, 2016; Arcara et al., 2019).

Another variable that, based on several studies, is included in normative data is sex (Halpern, 1996; Mann, Sasanuma, Sakuma, \& Masaki, 1990; Reilly, Neumann, \& Andrews, 2016). Although it is still under debate whether cognitive differences between sexes are related to brain differences or socio-cultural effects, as a matter of fact, males or females can perform differently on specific tests (Yeudall, Fromm, Reddon, \& Stefanyk, 1986; J. Zhang, Zhou, Wang, \& Zhang, 2017). To improve normative data, sex is often taken into account. For example, it has been found that scores on the MoCA (but not on the Mini-Mental State Examination score) are significantly influenced by sex: with women showing a higher performance on delayed recall and men showing a higher score on visuo-construction and serial subtraction (Engedal et al., 2021).

Another variable almost always included in normative data is education, often expressed in terms of years spent at school (Kittner et al., 1986). Education is a variable that can be easily collected and many empirical studies showed that the higher the education is, the higher the expected performance in cognitive tests (e.g., Chan et al., 2018; Le Carret et al., 2005, 2003; Stern, Alexander, Prohovnik, \& Mayeux, 1992). Also in the case of education, the effect on performance could be linear or non-linear as has been shown in previous studies (e.g., Arcara \& Bambini, 2016; Arcara et al., 2019).

It is important to underline that the positive relationship often expected between education and performance does not necessarily imply that education has a direct role on cognitive efficiency: other variables (e.g., socioeconomic status) may be confounded with the possibility to attain higher education and thus to maintain higher cognitive performance along with the lifespan (e.g., socio-economic status; see Jefferson et al., 2011). The observed relationship between education and cognitive performance, however, has gained greater importance in recent times. Many findings indeed have shown that early-life cognitive stimulation/enrichment at school age (or deprivation, considering it on a continuum) is associated with an efficient cognitive functioning in later life (Stern, 2002) and with the degree to which brain resources are accumulated and deployed (Katzman et al., 1989; Katzman et al., 1988; Zhang et al., 1990), suggesting a potentially causal role in cognition. From this perspective, education is strictly related to the concept of the Cognitive Reserve (CR, Stern, 2002).

CR allows accounting for the discrepancy between age-related brain changes and brain pathology and the relative manifestation in the cognitive domain. In other terms, CR "should help to account for individual differences in performance, given the same status of the brain” (Stern, Gazes, Razlighi, Steffener, \& Habeck, 
2018). In fact, the same magnitude in brain disruption can result in different levels of cognitive performance, and such levels may increase with higher CR proxies (Barulli \& Stern, 2013; Cabeza et al., 2018a; Stern, ArenazaUrquijo, et al., 2018). The most common proxy used to estimate CR is education (Borland et al., 2017; Busch \& Chapin, 2008; Cesar et al., 2019; Malek-Ahmadi et al., 2015; Siciliano et al., 2019). Albeit the importance of education as a proxy of $\mathrm{CR}$, its use has been considered conceptually problematic, as $\mathrm{CR}$ mechanism is unlikely to be represented only by the pathway between education and late-life cognition (Anatürk et al., 2021). Many studies in this field have underlined also the role of a comprehensive range of further stimulating life experiences that occur along with adulthood (e.g., socio-behavioral factors; Fratiglioni, Paillard-Borg, \& Winblad, 2004; Livingston et al., 2017; Reed et al., 2011; Stern, Arenaza-Urquijo, et al., 2018; Ward et al., 2015). The main activities considered in this context are occupational attainment and leisure-time activities (Snowdon, 1997; Snowdon et al., 1996; Stern et al., 1995; Stern, Tang, Denaro, \& Mayeux, 1995). The potential contribution of occupational attainment and leisure-time activities to CR can be estimated by weighting the type of activity, the effort required to perform it, as also the regularity with which it is carried out (e.g., Scarmeas, Levy, Tang, Manly, \& Stern, 2001; White et al., 1994). For instance, this applies to the different degrees in responsibility and demand of a specific job, as also to physical activities (e.g., sports) requiring regularity, resistance, and concentration, or to hobbies entailing learning new skills, like for example music or art courses.

The importance of considering education together with other socio-demographic variables, proven to act as protective factors in longitudinal studies (Mondini et al., 2021; Ward et al., 2015), strongly suggests that normative data may improve when considering composite proxies of CR in the calculation cut-off scores.

The Cognitive Reserve Index questionnaire (CRIq, Nucci, Mapelli, \& Mondini, 2012) allows to estimate CR from education, occupational activity, and leisure-time activity as they concur in building up the reserve (Chan et al., 2018; Livingston et al., 2017; Scarmeas \& Stern, 2003; Stern et al., 1995; Ward et al., 2015). The CRlq is translated into many languages and it has been used both for clinical and research purposes (Artemiadis et al., 2020; Lavrencic et al., 2018; Lee et al., 2019; Maiovis, Ioannidis, Gerasimou, Gotzamani-Psarrakou, \& Karacostas, 2018; Montemurro, Jarema, \& Mondini, 2021; Ozakbas et al., 2021). It has been also shown that, when using CRIq, the effect of $\mathrm{CR}$ significantly interacts with age in the expected cognitive performance (Montemurro, Mondini, \& Arcara, 2021); in particular, as age increases performance is typically worse, but not when CRIq score is high. However, it is not clear how the interaction between age and CR may change between another relevant demographic variable, that is sex, which has been shown to have potentially complex interplay with CR (Levine et al., 2021; Subramaniapillai, Almey, Natasha Rajah, \& Einstein, 2021).

The goal of the present study is two-fold.

First, it aims to investigate whether a life-experience proxy of CR could be a better predictor of performance as compared to education in healthy controls for a popular screening test like the Montreal Cognitive Assessment (MoCA; Nasreddine et al., 2005). MoCA is, to date, used worldwide by psychologists, neurologists, geriatricians, occupational and speech therapists (e.g., O'Driscoll \& Shaikh, 2017) and serves for a general screening, usually followed by a more detailed neuropsychological assessment of the cognitive profile. Initially created to distinguish among individuals with $\mathrm{MCl}$, Alzheimer's disease, and healthy controls, now widely used for assessing the cognitive profile of healthy participants (Chen et al., 2020; Montemurro, Mondini, Crovace, \& Jarema, 2019), populations with pathological aging (Roalf et al., 2013) and neurodegenerative disorders like 
Parkinson's Disease (Biundo et al., 2014; Montemurro et al., 2019), Multiple Sclerosis (e.g., Al-Sharman et al., 2019), and Human immunodeficiency virus (HIV) (Rosca, Albarqouni, \& Simu, 2019).

The second aim of the paper is to provide improved normative data and clinical cut-offs of MoCA for the italian population. Although other normative data are already available (Aiello et al., 2021; Conti, Bonazzi, Laiacona, Masina, \& Coralli, 2015; Pirrotta et al., 2015; Santangelo et al., 2015), this study aims to provide for the first time, normative data and cut-off scores accounting for a life-experience CR proxy.

\section{Method}

\section{1 Participants}

The participant sample included a total of 440 Italian healthy individuals ( 292 females, 148 males, Age range = 50-90 years old), all Italian native speakers and autonomous in their daily living activities. The individuals with a medical history of stroke, traumatic brain injury, or any neurological or psychiatric disease requiring medical treatment were not included in the normative data sample. All participants took part in this study after signing the Informed Consent. The Research Ethics Committee of the University of Milano-Bicocca approved this study (permit number: RM-2017-84) as a minimal risk study that adheres to the Declaration of Helsinki. We report the descriptive results associated with the demographic variables (Age, Education, and CRI) and the MoCA raw scores in Table 1.

Figure 1 shows the distribution of these variables in the two Sex groups (for further details about the distribution of these variables, see Figure S1 in Supplementary Materials). The sample included N=292 females, and $\mathrm{N}=148$ males.

\section{Mean SD Median Min Max Kurtosis Skewness Q1 Q3}

\begin{tabular}{lccccccccc}
\hline Age & 67.09 & 9.10 & 67 & 50 & 90 & -0.57 & 0.18 & 60 & 73 \\
\hline ducation & 11.25 & 4.58 & 12 & 3 & 27 & -0.48 & 0.27 & 8 & 13 \\
\hline CRI & 113.26 & 18.79 & 114 & 71 & 168 & -0.46 & 0.01 & 100 & 126 \\
\hline MoCA & 25.47 & 2.81 & 26 & 16 & 30 & 0.21 & -0.75 & 24 & 27 \\
\hline
\end{tabular}

ble 1. Descriptive statistics of the normative sample. Age and Education in years, CRI and MoCA raw score sorted in rows. Columns report mean, standard deviation, median, minimum value, maximum value, kuı swness, first quartile, and third quartile of each variable.

\subsection{Materials}


The MoCA test (Nasreddine et al., 2005) and the Cognitive Reserve Index questionnaire (CRIq, Nucci, Mapelli, \& Mondini, 2012) were administered to all participants.

- The MoCA is a cognitive screening. It assesses visuospatial/executive abilities, naming, memory, attention, language, abstract reasoning, and orientation (in time and space). Visuospatial and, to some extent, executive abilities are assessed using an adapted form of the clock-drawing task and a trail-making task (Reitan, 1958). Attention, concentration, and working memory are assessed through an auditory sustained attention task, a serial subtraction task, and forward and backward digit recall. MoCA has been proven to be more sensitive in detecting the level of general cognitive functioning, compared to the Mini-Mental State Examination (Ciesielska et al., 2016; Dong et al., 2010; Roalf et al., 2013). MoCA is available in over 30 languages and it can be administered in 10 minutes. Permission was obtained for the use of the MoCAC Test for this study, according to the official requirements (https://www.mocatest.org/).

- The Cognitive Reserve Index-questionnaire (CRIq) provides a global proxy of CR based on a range of cognitively stimulating life-experiences occurring throughout the lifespan. CRIq is freely available and translated in different languages [http://www.cognitivereserveindex.org].

A digital version of CRIq allows optimizing time for administration and scoring:

[http://www.cognitivereserveindex.org/calcolo/calcolo.html].

CRIq is a semi-structured interview including 20 questions tapping into the formal educational experience (CRIEducation), working activity (CRI-WorkingActivity), and leisure-time activity (CRI-LeisureTime). CRI-Education refers to the years of formal education achieved plus any course carried out during adulthood (from 18 years old) for at least 6 months. CRI-WorkingActivity refers to years of working occupation carried out throughout the lifespan. CRI-LeisureTime refers to the amount of social, intellectual, and physical activities carried out in adulthood and its frequency in time (e.g., reading books, paintings, volunteering, doing sport, etc.). Regarding CRI-Education, one point is assigned for every attended year of schooling and 0.5 points are assigned to every 6 months of vocational courses attended in adulthood. Regarding CRI-WorkingActivity, one point is assigned for each year spent working. Jobs were weighted differently in the calculation of the total CRI score; they were divided into 5 groups depending on cognitive load, as also responsibility and mental resources required. CRILeisureTime accounts for activities with usual weekly (e.g., reading newspapers, doing sport, using new technologies), monthly (e.g., voluntary work, playing music), and annual frequency (e.g., traveling, attending concerts, and/or conferences). We used the CRI total score for obtaining CR-based Italian normative data of MoCA. CRI is the average of CRI-Education, CRI-WorkingActivity, and CRI-LeisureTime (Nucci et al., 2012b) and it provides a comprehensive/composite proxy of CR. Table 2 shows a description of activities considered in the calculation of CRI. Administration lasted on average 15 minutes. We administered MoCA and CRIq to each participant. 


\section{Cognitive Reserve Index (CRI)}

\begin{tabular}{|c|c|c|}
\hline 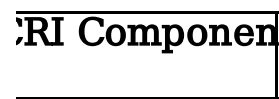 & Type of activity & $\begin{array}{l}\text { Frequency of occurrence of the activity considered in } \\
\text { the questionnaire }\end{array}$ \\
\hline Education & $\begin{array}{l}\text { Years of education } \\
\text { Vocational training }\end{array}$ & $\begin{array}{c}\text { (including postgraduate studies and any specialization, } \\
\text { vocational training of minimum } 6 \text { months) }\end{array}$ \\
\hline $\begin{array}{l}\text { Working } \\
\text { Activity }\end{array}$ & $\begin{array}{l}\text { Primary Job } \\
\text { Other Jobs carried out }\end{array}$ & $\begin{array}{l}\text { (five different levels are counted based on the level of } \\
\text { responsibility required) }\end{array}$ \\
\hline $\begin{array}{c}\text { Leisure- } \\
\text { Cime Activity }\end{array}$ & $\begin{array}{c}\text { Reading newspapers and } \\
\text { magazine } \\
\text { Housework activities } \\
\text { Driving } \\
\text { Leisure activities } \\
\text { ew technology use of device }\end{array}$ & (weekly frequency) \\
\hline & $\begin{array}{c}\text { Social activities } \\
\text { Cinema, theater } \\
\text { Gardening, handicraft, } \\
\text { knitting, embroidery } \\
\text { Grandchildren or elderly } \\
\text { caring } \\
\text { Volunteering } \\
\text { Artistic activities }\end{array}$ & (monthly frequency) \\
\hline & $\begin{array}{c}\text { Exhibitions, concerts, } \\
\text { conferences } \\
\text { Holidays } \\
\text { Reading books }\end{array}$ & (annual frequency) \\
\hline & $\begin{array}{c}\text { Children care } \\
\text { Managing the personal bank } \\
\text { account } \\
\text { Pet care }\end{array}$ & \\
\hline
\end{tabular}

ble 2. Activities considered in the Cognitive Reserve Index questionnaire (CRIq). The first column reports the $t$ nponents characterizing the CRIq: Education, Working Activities, and Leisure Activities; in the second column the actir ssidered for the computation of the score are listed; in the third column, the information regarding the regularity/frequ sccurrence of the activities accounted in the CRIq.

\subsection{Statistical Analyses}

All analysis were performed with the free statistical software R (R Development Core Team, 2021). 
The relationship between MoCA and Age, CRI, and Education (in terms of years) was first examined using a series of pairwise Pearson's correlations.

To investigate how $\mathrm{CRI}$ and Education predicted performance on MoCA, and to build the regression-based clinical cut-offs, we performed a series of regression analyses using demographic and socio-behavioural variables (i.e., Age, Sex, CRI, and Education) as predictors, and the score on MoCA as dependent variable

Before running the regression analysis we checked the potential occurrence of harmful collinearity between continuous predictors, which could harm model fit and interpretation. A preliminary check on potential collinearity was made by the inspection of the correlations, separately for each model. CRI showed a large correlation with Education [Pearson's $\mathrm{r}(438)=.75, \mathrm{p}<0.001$ ]. CRI showed a small correlation with Age [Pearson's $r(438)=-.20, p<0.001]$; Education showed a moderate correlation and Age [Pearson's $r(438)=-.38$ ]. To check the actual impact of collinearity on the results of the regressions, we calculated the Variance Inflation Factor associated with the variables of each model (VIF, Hair, Black, Babin, \& Anderson, 2010). As a rule-of-thumb, a VIF > 10 on a predictor indicates harmful collinearity, and no harmful collinearity was found (see Table S1 in Supplementary Material). We then analysed a series of linear regression models including MoCA score as dependent variable: Model 1 included Age and Sex as predictors, Model 2 included Age, Sex, and CRI, Model 3 included Age, Sex, and Education. Model 1 was included to have a simpler reference model and to test if including either Education or CRI led to an actual improvement in prediction. Then, a fourth model (Model 4) included both Education and CRI as predictors of MoCA scores. We checked the model diagnostics to inspect whether the assumptions for these linear regression models were met and we looked for outliers that could have influenced the regression estimates (if this was the case, we would have re-fitted the model excluding the outliers): the diagnostics did not show harmful results and none of the data points were identified as outliers based on Cook's Distance. We evaluated the results of model comparison based on Akaike Information Criterion (i.e., AIC, Sakamoto, Ishiguro, \& Kitagawa, 1986) and we also used $\mathrm{R}^{2}$ as a further measure to assess the quality of fit. The best-fitting model was further evaluated through the inspection of the partial residuals to check whether any non-linearity (i.e., curvilinear relationship) emerged between one predictor and the MoCA. For variables that showed a non-linear trend, we would have tested whether adding quadratic terms yielded better models. Following the procedure used in Arcara and Bambini, (2016) and Arcara and colleagues (2017), the quadratic term of CRI and Education were entered in Model 5 and Model 6, respectively. Finally, the quadratic terms of both CRI and Education were added in Model 7.

The AICs of these models 1-7 were compared: the model with the lowest AIC (i.e., the one that best fitted the data of our normative sample) was chosen for generating cut-offs using the regression method of Crawford and Garthwaite (2006). This method involves the calculation of the discrepancy between the observed and the predicted score from a regression model. The cut-offs are calculated as the scores delimiting a discrepancy that is expected to be obtained by less than $5 \%$ of the population, after predicting the score from the relevant variables. Shortly, a score falling below the cut-off indicates that the observed performance of an individual is unexpectedly low given the variables included in the model as predictors. The code used for cut-off calculation can be downloaded from https://github.com/giorgioarcara/R-codeMisc/tree/master/Crawford_and_Garthwaite_2006_R_code. 
Based on a previous investigation of our research group, in which it has been shown a relevant and selective interaction between Age and a composite life experience CR proxy (but not for Education) in individuals without age-related disease (Montemurro, Mondini, et al., 2021), we made an additional analysis to further explore such interaction. In line with the variables included in the study, we included in the additional analysis the variable Sex.

Generalized Additive Model analyses (GAMs; Hastie \& Tibshirani, 1986) were used to investigate the potential interaction between Age and CRI. The primary advantage of GAMs over linear regressions is their ability to efficiently treat, through smooth functions, complex non-linear relations between predictors and the dependent variable. GAMs allowed investigating the interaction between continuous variables through tensor surfaces, (something that cannot be handled by GLM); for a recent application of GAM with neuropsychological tests see Yu and colleagues, (2020); Montemurro, Mondini, and Arcara (2021). The reported p-values of the GAM analyses are corrected through the Bonferroni method according to the total number of tests performed. We used the package itsadug (van Rij, Wieling, Baayen, \& van Rijn, 2016) to inspect areas of significant interactions, and for data visualization, we overlaid a grey area when Confidence Interval (95\%) included 0 . The package $m g c v$ version 1.8-24 (Wood, 2017) was used to implement GAM models. Diagnostics were performed for both GLM and GAM models; all statistical analyses were performed in R version 4.0.1 (2020-06-06).

\section{Results}

MoCA score showed a moderate correlation with Age $[r(438)=-.41, p<.001]$, with $\operatorname{CRI}[r(438)=.42, p<.001]$, and with Education $[r(438)=.42, \mathrm{p}<.001]$. The variable Age linearly and significantly predicted MoCA scores in all the models: the higher the Age, the lower the MoCA scores. Inspection of the partial residuals in Models 1-4 indicated that Education and CRI were non linearly related with MoCA scores. Model 5, 6, and 7 were built to check whether including non-linear terms would improve the model fit. According to the AIC comparison and to Adjusted $\mathrm{R}^{2}$, the best model fit was Model 7, which included the demographic variables (Age and Sex), the two CR proxies (Education and CRI), and their quadratic terms (Education ${ }^{2}$ and $\mathrm{CRI}^{2}$ ); see Table 3. Model 7 predicted MoCA scores significantly better, compared to Model 4 ( $F=12.17, p=<0.001)$. Figure 2 shows the effect of Age CRI and Education on the MoCA score, based on the best model fit (Model 7). 
Linear Regression Model with MoCA score as a dependent variable

\begin{tabular}{|c|c|c|c|c|c|c|}
\hline & Term & Estimate (Standard Error) & t-value & $p$-value & Adjusted $\mathrm{R}^{2}$ & AIC (df) \\
\hline \multirow{3}{*}{ Model 1} & Intercept & $33.83(0.91)$ & 37.02 & $<.001^{*}$ & \multirow{3}{*}{0.16} & $2084.28(4)$ \\
\hline & Age & $-0.12(0.01)$ & -9.43 & $<.001 *$ & & \\
\hline & Sex & $0.24(0.26)$ & 0.94 & 0.37 & & \\
\hline \multirow[t]{4}{*}{ Model 2} & Intercept & $26.05(1.22)$ & 21.32 & $<.001^{*}$ & \multirow{4}{*}{0.28} & \multirow{4}{*}{$2014.50(5)$} \\
\hline & Age & $-0.10(0.01)$ & -8.22 & $<.001 *$ & & \\
\hline & Sex & $0.46(0.24)$ & 1.91 & 0.05 & & \\
\hline & CRI & $0.05(0.01)$ & 8.79 & $<.001 *$ & & \\
\hline \multirow[t]{4}{*}{ Model 3} & Intercept & $29.01(1.10)$ & 26.21 & $<.001 *$ & \multirow{4}{*}{0.24} & \multirow[t]{4}{*}{$2039.242(5)$} \\
\hline & Age & $-0.09(0.01)$ & -6.54 & $<.001 *$ & & \\
\hline & Sex & $0.53(0.25)$ & 2.11 & $0.03 *$ & & \\
\hline & Education & $0.19(0.02)$ & 7.01 & $<.001 *$ & & \\
\hline \multirow[t]{4}{*}{ Model 4} & $\begin{array}{c}\text { Intercept } \\
\text { Age }\end{array}$ & $\begin{array}{c}26.03(1.22) \\
0.49(0.24)\end{array}$ & $\begin{array}{l}21.31 \\
2.02\end{array}$ & $\begin{array}{l}<.001 * \\
0.04\end{array}$ & \multirow{4}{*}{0.28} & \multirow[t]{4}{*}{$2015.45(6)$} \\
\hline & Sex & $-0.10(0.01)$ & -7.36 & $<.001 *$ & & \\
\hline & Education & $0.04(0.04)$ & 1.01 & 0.31 & & \\
\hline & $C R I$ & $0.04(0.01)$ & 5.12 & $<.001 *$ & & \\
\hline \multirow[t]{5}{*}{ Model 5} & Intercept & $13.42(3.68)$ & 3.64 & 0.001 & \multirow{5}{*}{0.30} & \multirow{5}{*}{$2003.36(6)$} \\
\hline & Age & $-0.09(0.01)$ & -7.46 & $<.001 *$ & & \\
\hline & Sex & $0.53(0.24)$ & 2.22 & 0.02 & & \\
\hline & $C R I$ & $0.27(0.05)$ & 4.52 & $<.001$ & & \\
\hline & $C R I^{\wedge} 2$ & $-0.01(0.00)$ & -3.63 & $<.001 *$ & & \\
\hline \multirow[t]{4}{*}{ Model 6} & $\begin{array}{c}\text { Intercept } \\
\text { Age }\end{array}$ & $\begin{array}{l}25.28(1.31) \\
-0.07(0.01)\end{array}$ & $\begin{array}{l}19.21 \\
-5.61\end{array}$ & $\begin{array}{l}<0.001^{*} \\
<0.001^{*}\end{array}$ & \multirow{4}{*}{0.28} & $2017.35(6)$ \\
\hline & Sex & $0.53(0.24)$ & 2.18 & 0.03 & & \\
\hline & Education & $0.74(0.11)$ & 6.51 & $<0.001^{*}$ & & \\
\hline & Education $^{2}$ & $-0.02(0.00)$ & -4.92 & $<0.001 *$ & & \\
\hline \multirow{6}{*}{ Model 7} & $\begin{array}{c}\text { Intercept } \\
\text { Aoe }\end{array}$ & $\begin{array}{l}15.93(3.79) \\
-0.08(0.01)\end{array}$ & $\begin{array}{l}4.21 \\
-6.07\end{array}$ & $\begin{array}{l}<0.001 * \\
<0.001 *\end{array}$ & \multirow{6}{*}{0.32} & \multirow[t]{6}{*}{$1995.39(8)$} \\
\hline & Sex & $0.55(0.24)$ & 2.31 & $0.02 *$ & & \\
\hline & Education & $0.44(0.13)$ & 3.42 & $0.001 *$ & & \\
\hline & Education $^{2}$ & $-0.01(0.01)$ & -3.13 & $0.001 *$ & & \\
\hline & $C R I$ & $0.17(0.06)$ & 2.62 & $0.01 *$ & & \\
\hline & $C R I^{2}$ & $-0.00(C$ & -1.99 & $0.04^{*}$ & & \\
\hline
\end{tabular}

Table 3. Results of Regression Analyses with different demographic variables as predictors of interest and MoCA dependent variable. The table shows: the model name (first column); the name of the term entered in the regress model (second column); coefficient estimate and standard error within round brackets (third column); t-value associa with the term (fourth column); p-value (fifth column), with an asterisk "*" denoting significant terms; adjusted associated with each Model (sixth column); Akaike Information Criterion values (seventh column). The lowest the $t$ value, the better the model fit.

\subsection{Cut-off scores}

We calculated clinical cut-offs by applying the method of Crawford and Garthwaite (2006) to the results of Model 7. To calculate clinical cut-offs (i.e., reference scores that may help the interpretation of an observed performance in clinical contexts), values of MoCA associated with $p=0.05$ (according to Crawford method) 
were rounded to the nearest integer. Cut-offs of MoCA scores based on Age, Sex, CRI, and Education are reported in Table S2 of the Supplementary Material. This article is also accompanied by two online applications which allow to calculate (for a given observed score at MoCA) the exact p-value associated with the performance. The observed p-values and above/below cut-off performance can be calculated also using the online Application, available at: https://osf.io/y4jzs/

3.4 Additional analyses: Interaction between Age and CRI by Sex, through Generalized Additive Models (GAMs)

In the first GAM model, Age and CRI were entered as interacting continuous variables (Mod_int_1), with MoCA as the dependent variable. The syntax of this model is reported below:

Mod_int_1 <-gam (MoCA te(Age, CRI, k = c(5,5)), data = dataset)

In a second step, we entered Sex in the model as a factor with two levels, (i.e., males and females, Mod_int_2). The syntax of this model is reported below:

Mod_int_2 <- gam (MoCA Sex + te(Age, CRI, $k=c(5,5)$, by = Sex $)$, data = dataset $)$

Entering the factor Sex slightly improved the model fit (i.e., AIC of Mod_int_1 = 2007.08; AIC of Mod_int_2 = 2005.91). Namely, the best fitting model assessing the interaction between Age and CRI was the one in which Sex was included. The results of this model showed no significant main effect of $\operatorname{Sex}(B=-0.39, t=-1.63, p=$ 0.31 ), and a significant interaction between Age and CRI in both sexes (females: edf $=5.32, F=27.23, p<$ 0.001 ; males: edf $=3.01, \mathrm{~F}=8.10, p<0.001$ ), see Figure 3 . GAM analyses are characterized by parametric (or linear) terms, and smooth terms. Details about the results of the two GAM, and the terms are reported in Table 4. 


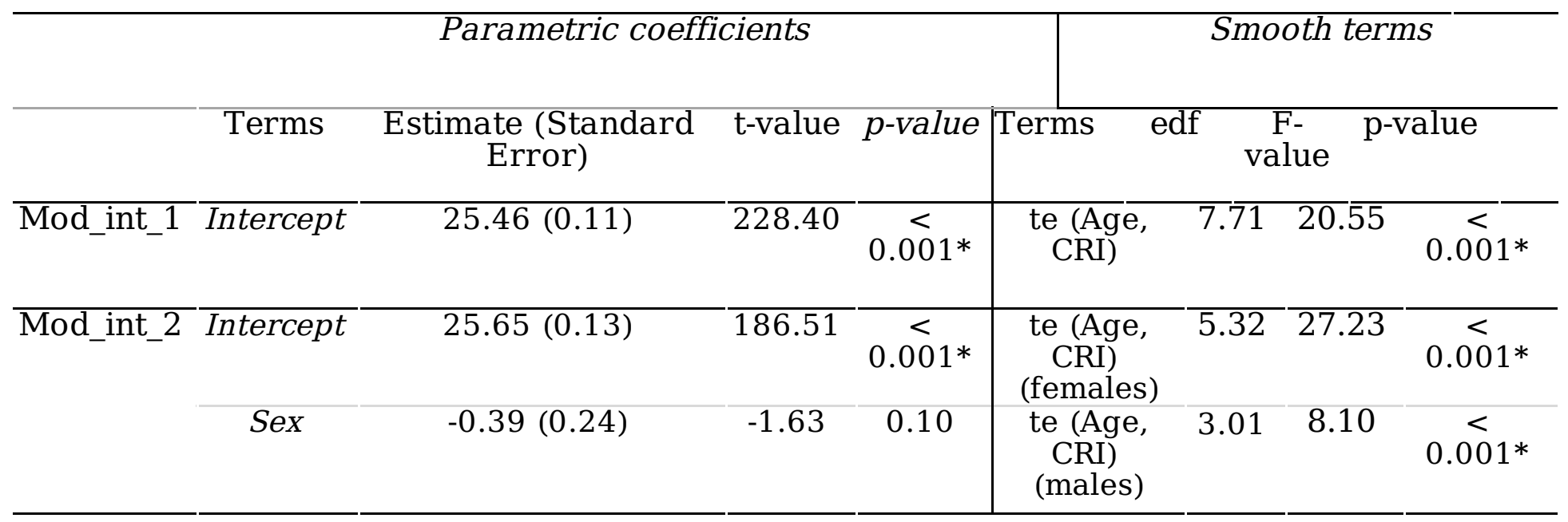

Table 4. Results of Generalized Additive Models with Age and Cognitive Reserve Index in interaction and MoCA dependent variable. The table shows, for the two GAM performed (model name in the first column), the result associa with the parametric coefficients (leftmost part of the table) and the smooth terms (rightmost part of the table). Within parametric coefficients, the table shows: names of parametric coefficients (terms, second column); coefficient estim and standard error within round brackets (third column); t-value associated with the parametric coefficient (for column); p-value associated with the parametric coefficient (fifth column), with an asterisk “*” denoting significant ter: Within the smooth terms, the table shows: names of smooth terms (sixth column); estimated degrees of freedom (seve column); F-value associated with the smooth terms (eighth column); p-values associated with the smooth terms, with asterisk “*” denoting significant terms.

Figure 3 shows the effect of CRI on MoCA for three different values of Age (i.e., 50, 70, and 90 years): higher MoCA scores were observed at the lower values of Age and the higher values of CRI. The interaction effect showed that the performance of participants with higher Age (that is when cognitive resources are decreasing with physiological decline) was more strongly and positively affected by CRI. Diagnostics of the GAM models showed non-harmful concurvity of the smooth terms, and the use of parameter $k$ was adequate (based on gam.check R function).

For a better interpretation of the GAM interaction between Age and CRI in the two sexes (Mod_int_2) we provide in the Supplementary materials a contour plot (Figure S2), which is used for interpreting GAM interactions among continuous variables.

\section{Discussion}

This study aimed at investigating whether a composite proxy of CR (CRI) based on life-experience could improve the prediction of cognitive performance, compared to considering Education as proxy of CR, leading to better normative data of the Montreal Cognitive Assessment, a short test used for cognitive screening (MoCA, Nasreddine et al., 2005). 
Both CRI and Education were positively associated with MoCA scores: the higher Education and the higher CRI, the better the performance, in line with previous findings in which a positive relationship between CR (estimated through Education and life-experience CR measures) and MoCA is highlighted (Kang et al., 2018; Kujawski et al., 2018; Peeters, Kenny, \& Lawlor, 2020).

However, our data show that considering a composite score of $\mathrm{CR}$, like CRI, results in a better prediction of the MoCA scores in healthy individuals, compared to using only Education. This was attested by different metrics evaluating the quality of fit of our models (i.e., AIC and $\mathrm{R}^{2}$ ). The predictive ability of $\mathrm{CRI}$ is in line with previous findings revealing that life-experiences proxies have a higher influence on cognitive function, compared to Education (in line for example with Reed et al., 2011, in which some activities considered were reading or attending concerts). Moreover, also at a qualitative inspection, CRI showed a better distribution compared to the variable Education (Figure S1 in Supplementary Material), suggesting CRI as a suitable variable for making predictions as it could potentially cover a more comprehensive range of influential life-experiences and differentiate the individuals of the normative sample.

The best-fitting model included Age and Sex together with CRI and Education. The variable Age exerted, as expected, a significant effect on MoCA scores, which were lower as Age increased, in line with previous literature (e.g., Malek-Ahmadi, O’Connor, Schofield, Coon, \& Zamrini, 2018; Wöbbeking-Sánchez, Bonete-López, Cabaco, Urchaga-Litago, \& Afonso, 2020). Sex was included as a further demographic characteristic that can predict different outcomes in cognitive performance (e.g., Reilly et al., 2016).

These results strengthen the importance of taking into account, in addition to the demographic characteristics and the educational level of the population, the inter-individual differences in carrying out a variety of potentially beneficial activities in adulthood: a point that has been considered crucial for prevention and healthcare (Livingston et al., 2017) and important for estimating more accurate normative data for clinical uses.

Our best-fitting model with Age, Sex, CRI and Educations as predictors of MoCA was used for deriving cut-off scores based on the regression-based method from Crawford and Garthwaite (2006). All cut-off scores are reported in the Supplementary Material (Table S2).

We also explored the potential age-related effect on performance, together with the modulatory role of CR estimated by $\mathrm{CRI}$, to better investigate the relationship between Age, CR, and performance, which has been recently shown to be potentially very complex (see Montemurro et al., 2021). Such interaction was modelled through Generalized Additive Models (GAMs, Hastie \& Tibshirani, 1986) which are suitable for evaluating complex relationships between continuous variables. This analysis showed that the patterns of MoCA smoothly changed along with the variations in Age and CRI. The higher the Age, the lower the performance at the MoCA test, but notably, this effect was modulated by CRI. On the other hand, the more the higher the CRI the higher the performance at the MoCA test, but this effect was significantly attenuated by Age.

Looking at demographic (like Age and Sex) and socio-behavioral variables (like CRI and Education), as potentially interplaying in determining the capacity of maintenance of the cognitive system (Anatürk et al., 
2021; Cabeza et al., 2018b; Stern, Barnes, Grady, Jones, \& Raz, 2019), is relevant and has been considered vastly important in a prevention perspective of the health care (Livingston et al., 2017).

Interestingly, potential differences between sexes could be expected in the compensatory effect of CR, il line with previous studies (e.g., Subramaniapillai et al., 2021). For this reason, in our additional analyses, we also explored the interaction between Age and CRI by entering Sex, in the GAM model of interest. Albeit no statistical differences involving Sex have been found, the group of females, especially at the oldest Age seemed to benefit more from higher CR, compared to the group of males. This result is compatible with previous studies showing how some relevant contributors to $\mathrm{CR}$, like Education, occupation, as also physical activity) are highly gendered. Historically, as compared to males, females have had less access to CR determinants (see Cohen, 2007 for more details related to the Italian background) which might have contributed, for a certain period, to the higher rates of cognitive decline in women, compared to males (Farrer et al., 1997; Mielke, Vemuri, \& Rocca, 2014). However, future studies are necessary to shed further light on this point.

Limitations and further implications

Some limitations can be associated with the calculation of normative data including life-experience proxies of CR: while Age and Education can be easily collected in a few seconds, the administration of tools estimating life-experience CR proxies may require additional time, which should face possible constraints of clinical assessments.

Moreover, it is important to consider that the CRlq is not the only tool that can be used to obtain a lifeexperience proxy of CR (see for example Altieri et al., 2018; Leoń, Garciá-García, \& Roldań-Tapia, 2014; Valenzuela \& Sachdev, 2007); other questionnaires or scales may even outperform the predictive performance of CRIq (Kartschmit, Mikolajczyk, Schubert, \& Lacruz, 2019) and in turn, the accuracy of calculated cut-offs. We used the CRIq since it is a validated and versatile instrument that has been widely used for estimating CR in some previous researches (Artemiadis et al., 2020; Lavrencic et al., 2018; Lee et al., 2019; Maiovis et al., 2018; Ozakbas et al., 2021). Here, for the first time, we show how it can be used to build more accurate normative data for clinical uses. Future studies may consider the possibility of obtaining Italian normative data of MoCA based on the complex interaction between demographic and socio-behavioral variables, as those obtained with GAM, which may need the development of appropriate statistical models, for drawing useful clinical conclusions

Overall, the present study suggests that including more detailed demographic and socio-behavioral interindividual information can foster the development of a more tailored approach in obtaining normative data, which is a crucial aspect for clinical assessments and health care.

\section{Declarations}

On behalf of all authors, the corresponding author states that there is no conflict of interest. 


\section{Bibliography}

Aiello, E. N., Gramegna, C., Esposito, A., Gazzaniga, V., Zago, S., Difonzo, T., ... Bolognini, N. (2021). The Montreal Cognitive Assessment (MoCA): updated norms and psychometric insights into adaptive testing from healthy individuals in Northern Italy. Aging Clinical and Experimental Research. https://doi.org/10.1007/s40520-02101943-7

Al-Sharman, A., Khalil, H., El-Salem, K., Alghwiri, A. A., Khazaaleh, S., \& Khraim, M. (2019). Motor performance improvement through virtual reality task is related to fatigue and cognition in people with multiple sclerosis. Physiotherapy Research International, 24(4). https://doi.org/10.1002/pri.1782

Altieri, M., Siciliano, M., Pappacena, S., Roldán-Tapia, M. D., Trojano, L., \& Santangelo, G. (2018). Psychometric properties of the Italian version of the Cognitive Reserve Scale (I-CRS). Neurological Sciences, 39(8), 13831390. https://doi.org/10.1007/s10072-018-3432-0

Anatürk, M., Kaufmann, T., Cole, J. H., Suri, S., Griffanti, L., Zsoldos, E., ... de Lange, A. M. G. (2021). Prediction of brain age and cognitive age: Quantifying brain and cognitive maintenance in aging. Human Brain Mapping, 42(6). https://doi.org/10.1002/hbm.25316

Arcara, G., \& Bambini, V. (2016). A test for the assessment of Pragmatic Abilities and Cognitive Substrates (APACS): Normative data and psychometric properties. Frontiers in Psychology, 7(FEB), 1-13. https://doi.org/10.3389/fpsyg.2016.00070

Arcara, G., Burgio, F., Benavides-Varela, S., Toffano, R., Gindri, P., Tonini, E., ... Semenza, C. (2019). Numerical Activities of Daily Living-Financial (NADL-F): A tool for the assessment of financial capacitiesł. Neuropsychological Rehabilitation, 29(7). https://doi.org/10.1080/09602011.2017.1359188

Arcara, G., Mondini, S., Bisso, A., Palmer, K., Meneghello, F., \& Semenza, C. (2017). The relationship between cognitive reserve and math abilities. Frontiers in Aging Neuroscience, 9(December).

https://doi.org/10.3389/fnagi.2017.00429

Artemiadis, A., Bakirtzis, C., Ifantopoulou, P., Zis, P., Bargiotas, P., Grigoriadis, N., \& Hadjigeorgiou, G. (2020). The role of cognitive reserve in multiple sclerosis: A cross-sectional study in 526 patients. Multiple Sclerosis and Related Disorders, 41. https://doi.org/10.1016/j.msard.2020.102047

Barulli, D., \& Stern, Y. (2013). Emerging Concepts in Cognitive Reserve. Trends Cognitive Sciences, 17(10), 1-17. https://doi.org/10.1016/j.tics.2013.08.012.Efficiency

Biundo, R., Weis, L., Facchini, S., Formento-Dojot, P., Vallelunga, A., Pilleri, M., \& Antonini, A. (2014). Cognitive profiling of Parkinson disease patients with mild cognitive impairment and dementia. Parkinsonism and Related Disorders, 20(4), 394-399. https://doi.org/10.1016/j.parkreldis.2014.01.009

Borland, E., Nägga, K., Nilsson, P. M., Minthon, L., Nilsson, E. D., \& Palmqvist, S. (2017). The Montreal Cognitive Assessment: Normative Data from a Large Swedish Population-Based Cohort. Journal of Alzheimer's Disease, 59(3). https://doi.org/10.3233/JAD-170203 
Busch, R. M., \& Chapin, J. S. (2008). Review of normative data for common screening measures used to evaluate cognitive functioning in elderly individuals. Clinical Neuropsychologist, Vol. 22.

https://doi.org/10.1080/13854040701448793

Cabeza, R., Albert, M., Belleville, S., Craik, F. I. M., Duarte, A., Grady, C. L., ... Rajah, M. N. (2018a). Maintenance, reserve and compensation: the cognitive neuroscience of healthy ageing. Nature Reviews Neuroscience, 19(11), 701-710. https://doi.org/10.1038/s41583-018-0068-2

Cabeza, R., Albert, M., Belleville, S., Craik, F. I. M., Duarte, A., Grady, C. L., ... Rajah, M. N. (2018b, November 1). Maintenance, reserve and compensation: the cognitive neuroscience of healthy ageing. Nature Reviews Neuroscience, Vol. 19, pp. 701-710. Nature Publishing Group. https://doi.org/10.1038/s41583-018-0068-2

Cesar, K. G., Yassuda, M. S., Porto, F. H. G., Brucki, S. M. D., \& Nitrini, R. (2019). MoCA Test: normative and diagnostic accuracy data for seniors with heterogeneous educational levels in Brazil. Arquivos de NeuroPsiquiatria, 77(11). https://doi.org/10.1590/0004-282X20190130

Chan, D., Shafto, M., Kievit, R., Matthews, F., Spink, M., Valenzuela, M., \& Henson, R. N. (2018). Lifestyle activities in mid-life contribute to cognitive reserve in late-life, independent of education, occupation, and late-life activities. Neurobiology of Aging. https://doi.org/10.1016/j.neurobiolaging.2018.06.012

Chen, L. K., Hwang, A. C., Lee, W. J., Peng, L. N., Lin, M. H., Neil, D. L., ... Chiou, S. T. (2020). Efficacy of multidomain interventions to improve physical frailty, depression and cognition: data from cluster-randomized controlled trials. Journal of Cachexia, Sarcopenia and Muscle, 11(3). https://doi.org/10.1002/jcsm.12534

Ciesielska, N., Sokołowski, R., Mazur, E., Podhorecka, M., Polak-Szabela, A., \& Kędziora-Kornatowska, K. (2016). Is the Montreal Cognitive Assessment (MoCA) test better suited than the Mini-Mental State Examination (MMSE) in mild cognitive impairment $(\mathrm{MCl})$ detection among people aged over 60 ? Meta-analysis. Psychiatria Polska, 50(5). https://doi.org/10.12740/pp/45368

Cohen, E. S. (2007). Chapter Eleven. Evolving the History of Women in Early Modern Italy: Subordination and Agency. In Medieval and Early Modern Iberian World(Vol. 32). https://doi.org/10.1163/ej.9789004154292.i606.49

Conti, S., Bonazzi, S., Laiacona, M., Masina, M., \& Coralli, M. V. (2015). Montreal Cognitive Assessment (MoCA)Italian version: regression based norms and equivalent scores. Neurological Sciences.

https://doi.org/10.1007/s10072-014-1921-3

Crawford, J. R., Howell, D. C., \& Garthwaite, P. H. (1998). Payne and Jones revisited: Estimating the abnormality of test score differences using a modified paired samples t test. Journal of Clinical and Experimental Neuropsychology, 20(6). https://doi.org/10.1076/jcen.20.6.898.1112

Crawford, John R., \& Garthwaite, P. H. (2006). Comparing patients' predicted test scores from a regression equation with their obtained scores: A significance test and point estimate of abnormality with accompanying confidence limits. Neuropsychology, 20(3), 259-271. https://doi.org/10.1037/0894-4105.20.3.259 
Crawford, John R., Garthwaite, P. H., \& Porter, S. (2010). Point and interval estimates of effect sizes for the casecontrols design in neuropsychology: Rationale, methods, implementations, and proposed reporting standards. Cognitive Neuropsychology, 27(3), 245-260. https://doi.org/10.1080/02643294.2010.513967

Dong, Y., Sharma, V. K., Chan, B. P. L., Venketasubramanian, N., Teoh, H. L., Seet, R. C. S., ... Chen, C. (2010). The Montreal Cognitive Assessment (MoCA) is superior to the Mini-Mental State Examination (MMSE) for the detection of vascular cognitive impairment after acute stroke. Journal of the Neurological Sciences, 299(1-2). https://doi.org/10.1016/j.jns.2010.08.051

Engedal, K., Gjøra, L., Bredholt, T., Thingstad, P., Tangen, G. G., Ernstsen, L., \& Selbæk, G. (2021). Sex Differences on Montreal Cognitive Assessment and Mini-Mental State Examination Scores and the Value of Self-Report of Memory Problems among Community Dwelling People 70 Years and above: The HUNT Study. Dementia and Geriatric Cognitive Disorders. https://doi.org/10.1159/000516341

Farrer, L. A., Cupples, L. A., Haines, J. L., Hyman, B., Kukull, W. A., Mayeux, R., ... Van Duijn, C. M. (1997). Effects of age, sex, and ethnicity on the association between apolipoprotein $E$ genotype and Alzheimer disease: A meta-analysis. Journal of the American Medical Association, Vol. 278.

https://doi.org/10.1001/jama.278.16.1349

Fratiglioni, L., Paillard-Borg, S., \& Winblad, B. (2004). An active and socially integrated lifestyle in late life might protect against dementia. Lancet Neurology. https://doi.org/10.1016/S1474-4422(04)00767-7

Hair, J. F., Black, W. C., Babin, B. J., \& Anderson, R. E. (2010). Multivariate data analysis (7th ed.; Englewood Cliffs: Prentice Hall, Ed.).

Halpern, D. F. (1996). Public policy implications of sex differences in cognitive abilities. Psychology, Public Policy, and Law, 2(3-4). https://doi.org/10.1037/1076-8971.2.3-4.561

Hastie, T., \& Tibshirani, R. (1986). Generalized additive models. Statistical Science, 1(3). https://doi.org/10.1214/ss/1177013604

Hohman, T. J., Tommet, D., Marks, S., Contreras, J., Jones, R., \& Mungas, D. (2017). Evaluating Alzheimer's disease biomarkers as mediators of age-related cognitive decline. Neurobiology of Aging, 58. https://doi.org/10.1016/j.neurobiolaging.2017.06.022

Jefferson, A. L., Gibbons, L. E., Rentz, D. M., Carvalho, J. O., Manly, J., Bennett, D. A., \& Jones, R. N. (2011). A life course model of cognitive activities, socioeconomic status, education, reading ability, and cognition. Journal of the American Geriatrics Society. https://doi.org/10.1111/j.1532-5415.2011.03499.x

Jockwitz, C., Mérillat, S., Liem, F., Oschwald, J., Amunts, K., Caspers, S., \& Jäncke, L. (2019). Generalizing age effects on brain structure and cognition: A two-study comparison approach. Human Brain Mapping, 40(8). https://doi.org/10.1002/hbm.24524

Kang, J. M., Cho, Y. S., Park, S., Lee, B. H., Sohn, B. K., Choi, C. H., ... Lee, J. Y. (2018). Montreal cognitive assessment reflects cognitive reserve. BMC Geriatrics, 18(1). https://doi.org/10.1186/s12877-018-0951-8 
Kartschmit, N., Mikolajczyk, R., Schubert, T., \& Lacruz, M. E. (2019). Measuring Cognitive Reserve (CR) - A systematic review of measurement properties of CR questionnaires for the adult population. PLOS ONE, 14(8). https://doi.org/10.1371/journal.pone.0219851

Katzman, R., Aronson, M., Fuld, P., Kawas, C., Brown, T., Morgenstern, H., ... Ooi, W. L. (1989). Development of dementing illnesses in an 80-year-old volunteer cohort. Annals of Neurology, 25(4), 317-324.

https://doi.org/10.1002/ana.410250402

Katzman, Robert, Terry, R., DeTeresa, R., Brown, T., Davies, P., Fuld, P., ... Peck, A. (1988). Clinical, pathological, and neurochemical changes in dementia: A subgroup with preserved mental status and numerous neocortical plaques. Annals of Neurology, 23(2), 138-144. https://doi.org/10.1002/ana.410230206

Kittner, S. J., White, L. R., Farmer, M. E., Wolz, M., Kaplan, E., Moes, E., ... Feinleib, M. (1986). Methodological issues in screening for dementia: The problem of education adjustment. Journal of Chronic Diseases, 39(3). https://doi.org/10.1016/0021-9681(86)90019-6

Kopecek, M., Stepankova, H., Lukavsky, J., Ripova, D., Nikolai, T., \& Bezdicek, O. (2017). Montreal cognitive assessment (MoCA): Normative data for old and very old Czech adults. Applied Neuropsychology:Adult, 24(1). https://doi.org/10.1080/23279095.2015.1065261

Kujawski, S., Kujawska, A., Gajos, M., Topka, W., Perkowski, R., Androsiuk-Perkowska, J., ... KędzioraKornatowska, K. (2018). Cognitive functioning in older people. Results of the first wave of cognition of older people, education, recreational activities, nutrition, comorbidities, functional capacity studies (COPERNICUS). Frontiers in Aging Neuroscience, 10. https://doi.org/10.3389/fnagi.2018.00421

Lavrencic, L. M., Richardson, C., Harrison, S. L., Muniz-Terrera, G., Keage, H. A. D., Brittain, K., ... Stephan, B. C. M. (2018). Is There a Link between Cognitive Reserve and Cognitive Function in the Oldest-Old? Journals of Gerontology - Series A Biological Sciences and Medical Sciences, 73(4). https://doi.org/10.1093/gerona/glx140

Le Carret, N., Auriacombe, S., Letenneur, L., Bergua, V., Dartigues, J. F., \& Fabrigoule, C. (2005). Influence of education on the pattern of cognitive deterioration in AD patients: The cognitive reserve hypothesis. Brain and Cognition, 57(2), 120-126. https://doi.org/10.1016/j.bandc.2004.08.031

Le Carret, N., Lafont, S., Letenneur, L., Dartigues, J. F., Mayo, W., \& Fabrigoule, C. (2003). The effect of education on cognitive performances and its implication for the constitution of the cognitive reserve. Developmental Neuropsychology. https://doi.org/10.1207/S15326942DN2303_1

Lee, D. H., Lee, P., Seo, S. W., Roh, J. H., Oh, M., Oh, J. S., ... Jeong, Y. (2019). Neural substrates of cognitive reserve in Alzheimer's disease spectrum and normal aging. Neurolmage, 186, 690-702.

https://doi.org/10.1016/j.neuroimage.2018.11.053

Leoń, I., Garciá-García, J., \& Roldań-Tapia, L. (2014). Estimating cognitive reserve in healthy adults using the cognitive reserve scale. PLoS ONE, 9(7). https://doi.org/10.1371/journal.pone.0102632

Levine, D. A., Gross, A. L., Briceño, E. M., Tilton, N., Giordani, B. J., Sussman, J. B., ... Galecki, A. T. (2021). Sex Differences in Cognitive Decline among US Adults. JAMA Network Open, 4(2). 
Livingston, G., Sommerlad, A., Orgeta, V., Costafreda, S. G., Huntley, J., Ames, D., ... Mukadam, N. (2017). Dementia prevention, intervention, and care. The Lancet, Vol. 390. https://doi.org/10.1016/S01406736(17)31363-6

Madden, D. J., Jain, S., Monge, Z. A., Cook, A. D., Lee, A., Huang, H., ... Cohen, J. R. (2020). Influence of structural and functional brain connectivity on age-related differences in fluid cognition. Neurobiology of Aging, 96. https://doi.org/10.1016/j.neurobiolaging.2020.09.010

Maiovis, P., loannidis, P., Gerasimou, G., Gotzamani-Psarrakou, A., \& Karacostas, D. (2018). Cognitive Reserve Hypothesis in Frontotemporal Dementia: Evidence from a Brain SPECT Study in a Series of Greek Frontotemporal Dementia Patients. Neurodegenerative Diseases, 18(2-3). https://doi.org/10.1159/000486621

Malek-Ahmadi, M., O'Connor, K., Schofield, S., Coon, D. W., \& Zamrini, E. (2018). Trajectory and variability characterization of the Montreal cognitive assessment in older adults. Aging Clinical and Experimental Research, 30(8). https://doi.org/10.1007/s40520-017-0865-x

Malek-Ahmadi, M., Powell, J. J., Belden, C. M., Oconnor, K., Evans, L., Coon, D. W., \& Nieri, W. (2015). Age-and education-adjusted normative data for the Montreal Cognitive Assessment (MoCA) in older adults age 70-99. Aging, Neuropsychology, and Cognition, 22(6). https://doi.org/10.1080/13825585.2015.1041449

Mann, V. A., Sasanuma, S., Sakuma, N., \& Masaki, S. (1990). Sex differences in cognitive abilities: A crosscultural perspective. Neuropsychologia, 28(10). https://doi.org/10.1016/0028-3932(90)90141-A

Mielke, M. M., Vemuri, P., \& Rocca, W. A. (2014). Clinical epidemiology of Alzheimer's disease: Assessing sex and gender differences. Clinical Epidemiology, Vol. 6. https://doi.org/10.2147/CLEP.S37929

Mondini, S., Pucci, V., Montemurro, S., Rumiati, R.I. (under review to the European Journal of Neurology). Protective factors for cognitive decline: Trajectories and changes in a longitudinal study with Italian elderly.

Montemurro, S., Mondini, S., Signorini, M., Marchetto, A., Bambini, V., \& Arcara, G. (2019). Pragmatic language disorder in Parkinson's disease and the potential effect of cognitive reserve. Frontiers in Psychology, 10(JUN). https://doi.org/10.3389/fpsyg.2019.01220

Montemurro, Jarema, G., \& Mondini, S. (2021). Cognitive Reserve and language processing demand in healthy older adults. Language, Cognition and Neuroscience, $0(0), 1-15$.

https://doi.org/10.1080/23273798.2021.1896012

Montemurro, Sonia, Mondini, S., \& Arcara, G. (2021). Heterogeneity of Effects of Cognitive Reserve on Performance in Probable Alzheimer's Disease and in Subjective Cognitive Decline. Neuropsycholog.

Montemurro, Sonia, Mondini, S., Crovace, C., \& Jarema, G. (2019). Cognitive Reserve and Its Effect in Older Adults on Retrieval of Proper Names, Logo Names and Common Nouns. Frontiers in Communication. https://doi.org/10.3389/fcomm.2019.00014 
Montemurro, Sonia, Mondini, S., Nucci, M., \& Semenza, C. (2018). Proper name retrieval in cognitive decline The role of cognitive reserve. Mental Lexicon Journal, 2, 215-231.

Nasreddine, Z. S., Phillips, N. A., Bédirian, V., Charbonneau, S., Whitehead, V., Collin, I., ... Chertkow, H. (2005a). The Montreal Cognitive Assessment, MoCA: a brief screening tool for mild cognitive impairment. Journal of the American Geriatrics Society, 53(4), 695-699. https://doi.org/10.1111/j.1532-5415.2005.53221.x

Nasreddine, Z. S., Phillips, N. a, Bédirian, V., Charbonneau, S., Whitehead, V., Collin, I., ... Chertkow, H. (2005b). The Montreal Cognitive Assessment, MoCA: a brief screening tool for mild cognitive impairment. Journal of the American Geriatrics Society, 53(4), 695-699. https://doi.org/10.1111/j.1532-5415.2005.53221.x

Nucci, M., Mapelli, D., \& Mondini, S. (2012a). Cognitive Reserve Index questionnaire (CRIq): a new instrument for measuring cognitive reserve. Aging Clinical and Experimental Research, 24(3), 218-226.

https://doi.org/10.3275/7800

Nucci, M., Mapelli, D., \& Mondini, S. (2012b). Cognitive Reserve Index questionnaire (CRIq): a new instrument for measuring cognitive reserve. Aging Clin Exp ResAging Clin Exp Res. https://doi.org/10.3275/7800

O’Driscoll, C., \& Shaikh, M. (2017). Cross-Cultural Applicability of the Montreal Cognitive Assessment (MoCA): A Systematic Review. Journal of Alzheimer's Disease, Vol. 58. https://doi.org/10.3233/JAD-161042

Ozakbas, S., Yigit, P., Akyuz, Z., Sagici, O., Abasiyanik, Z., Ozdogar, A. T., ... Hosgel, I. (2021). Validity and reliability of "Cognitive Reserve Index Questionnaire" for the Turkish Population. Multiple Sclerosis and Related Disorders, 50. https://doi.org/10.1016/j.msard.2021.102817

Peeters, G., Kenny, R. A., \& Lawlor, B. (2020). Late life education and cognitive function in older adults. International Journal of Geriatric Psychiatry, 35(6). https://doi.org/10.1002/gps.5281

Pirrotta, F., Timpano, F., Bonanno, L., Nunnari, D., Marino, S., Bramanti, P., \& Lanzafame, P. (2015). Italian validation of Montreal cognitive assessment. European Journal of Psychological Assessment, 31(2). https://doi.org/10.1027/1015-5759/a000217

Proust-Lima, C., Amieva, H., Dartigues, J. F., \& Jacqmin-Gadda, H. (2007). Sensitivity of four psychometric tests to measure cognitive changes in brain aging-population-based studies. American Journal of Epidemiology, 165(3). https://doi.org/10.1093/aje/kwk017

Reed, B. R., Dowling, M., Tomaszewski Farias, S., Sonnen, J., Strauss, M., Schneider, J. A., ... Mungas, D. (2011). Cognitive activities during adulthood are more important than education in building reserve. Journal of the International Neuropsychological Society, 17(4), 615-624. https://doi.org/10.1017/S1355617711000014

Reilly, D., Neumann, D. L., \& Andrews, G. (2016). Sex and sex-role differences in specific cognitive abilities. Intelligence, 54. https://doi.org/10.1016/j.intell.2015.12.004

Reitan, R. M. (1958). Validity of the Trail Making Test as an Indicator of Organic Brain Damage. Perceptual and Motor Skills, 8(3). https://doi.org/10.2466/pms.1958.8.3.271 
Roalf, D. R., Moberg, P. J., Xie, S. X., Wolk, D. A., Moelter, S. T., \& Arnold, S. E. (2013). Comparative accuracies of two common screening instruments for classification of Alzheimer's disease, mild cognitive impairment, and healthy aging. Alzheimer's and Dementia, 9(5). https://doi.org/10.1016/j.jalz.2012.10.001

Rosca, E. C., Albarqouni, L., \& Simu, M. (2019). Montreal Cognitive Assessment (MoCA) for HIV-Associated Neurocognitive Disorders. Neuropsychology Review, Vol. 29. https://doi.org/10.1007/s11065-019-09412-9

Sakamoto, Y., Ishiguro, M., \& Kitagawa, G. (1986). Akaike information criterion statistics. Tokyo; Dordrecht; Boston; Hingham, MA: KTK Scientific Publishers; D. Reidel; Sold and distributed in the U.S.A. and Canada by Kluwer Academic Publishers.

Salthouse, T. A. (1993). Speed and knowledge as determinants of adult age differences in verbal tasks. Journals of Gerontology, 48(1). https://doi.org/10.1093/geronj/48.1.P29

Salthouse, Timothy A. (1996). The Processing-Speed Theory of Adult Age Differences in Cognition. Psychological Review, 103(3). https://doi.org/10.1037/0033-295X.103.3.403

Santangelo, G., Siciliano, M., Pedone, R., Vitale, C., Falco, F., Bisogno, R., ... Trojano, L. (2015). Normative data for the Montreal Cognitive Assessment in an Italian population sample. Neurological Sciences, 36(4).

https://doi.org/10.1007/s10072-014-1995-y

Scarmeas, N, Levy, G., Tang, M. X., Manly, J., \& Stern, Y. (2001). Influence of leisure activity on the incidence of Alzheimer's disease. Neurology.

Scarmeas, Nikolaos, \& Stern, Y. (2003). Cognitive Reserve and Lifestyle. Journal of Clinical and Experimental Neuropsychology. https://doi.org/10.1076/jcen.25.5.625.14576

Siciliano, M., Chiorri, C., Passaniti, C., Sant'Elia, V., Trojano, L., \& Santangelo, G. (2019). Comparison of alternate and original forms of the Montreal Cognitive Assessment (MoCA): an Italian normative study. Neurological Sciences, 40(4). https://doi.org/10.1007/s10072-019-3700-7

Snowdon, D. (1997). Aging and Alzheimer's disease: lessons from the Nun Study. Gerontologist., 37(2), 150156.

Snowdon, D. A., Kemper, S. J., Mortimer, J. A., Greiner, L. H., Wekstein, D. R., \& Markesbery, W. R. (1996). Linguistic ability in early life and cognitive function and Alzheimer's disease in late life: Findings from the Nun Study. JAMA: The Journal of the American Medical Association, 275(7), 528-532.

https://doi.org/10.1001/jama.1996.03530310034029

Stern, Y, Alexander, G. E., Prohovnik, I., Stricks, L., Link, B., Lennon, M. C., \& Mayeux, R. (1995). Relationship between lifetime occupation and parietal flow. Neurology, 45(1), 55 LP - 60.

https://doi.org/10.1212/WNL.45.1.55

Stern, Yaakov. (2002). What is cognitive reserve? Theory and research application of the reserve concept. Journal of the International Neuropsychological Society, 8, 448-460. 
Stern, Yaakov, Alexander, G. E., Prohovnik, I., \& Mayeux, R. (1992). Inverse relationship between education and parietotemporal perfusion deficit in Alzheimer's disease. Annals of Neurology.

https://doi.org/10.1002/ana.410320311

Stern, Yaakov, Arenaza-Urquijo, E. M., Bartrés-Faz, D., Belleville, S., Cantilon, M., Chetelat, G., ... Vuoksimaa, E. (2018). Whitepaper: Defining and investigating cognitive reserve, brain reserve, and brain maintenance. Alzheimer's and Dementia. https://doi.org/10.1016/j.jalz.2018.07.219

Stern, Yaakov, Barnes, C. A., Grady, C., Jones, R. N., \& Raz, N. (2019). Brain reserve, cognitive reserve, compensation, and maintenance: operationalization, validity, and mechanisms of cognitive resilience. Neurobiology of Aging, 83, 124-129. https://doi.org/10.1016/j.neurobiolaging.2019.03.022

Stern, Yaakov, Gazes, Y., Razlighi, Q., Steffener, J., \& Habeck, C. (2018). A task-invariant cognitive reserve network. Neurolmage, 178. https://doi.org/10.1016/j.neuroimage.2018.05.033

Stern, Yaakov, Tang, M. X., Denaro, J., \& Mayeux, R. (1995). Increased risk of mortality in alzheimer's disease patients with more advanced educational and occupational attainment. Annals of Neurology. https://doi.org/10.1002/ana.410370508

Strauss, E., Sherman, E. M. S., \& Spreen, O. (2006). A Compendium of Neuropsychological Tests: Administration, Norms, and Commentary. Oxford University Press; 3rd edition (April 6, 2006).

Subramaniapillai, S., Almey, A., Natasha Rajah, M., \& Einstein, G. (2021). Sex and gender differences in cognitive and brain reserve: Implications for Alzheimer's disease in women. Frontiers in Neuroendocrinology, Vol. 60. https://doi.org/10.1016/j.yfrne.2020.100879

Valenzuela, M. J., \& Sachdev, P. (2007). Assessment of complex mental activity across the lifespan: Development of the Lifetime of Experiences Questionnaire (LEQ). Psychological Medicine. https://doi.org/10.1017/S003329170600938X

van Rij, J., Wieling, M., Baayen, R. H., \& van Rijn, H. (2016). itsadug: Interpreting time series and autocorrelated data using gamms. $R$ Package Version.

Verhaeghen, P. (2003). Aging and vocabulary scores: A meta-analysis. Psychology and Aging, 18(2). https://doi.org/10.1037/0882-7974.18.2.332

Verhaeghen, P., \& Salthouse, T. A. (1997). Meta-analyses of age-cognition relations in adulthood: Estimates of linear and nonlinear age effects and structural models. Psychological Bulletin, 122(3).

https://doi.org/10.1037/0033-2909.122.3.231

Ward, D. D., Summers, M. J., Saunders, N. L., Ritchie, K., Summers, J. J., \& Vickers, J. C. (2015). The BDNF Val66Met polymorphism moderates the relationship between cognitive reserve and executive function. Translational Psychiatry, 5(6). https://doi.org/10.1038/tp.2015.82

White, L., Katzman, R., Losonczy, K., Salive, M., Wallace, R., Berkman, L., ... Havlik, R. (1994). Association of education with incidence of cognitive impairment in three established populations for epidemiologic studies of 
the elderly. Journal of Clinical Epidemiology, 47(4), 363-374. https://doi.org/10.1016/0895-4356(94)90157-0

Wöbbeking-Sánchez, M., Bonete-López, B., Cabaco, A. S., Urchaga-Litago, J. D., \& Afonso, R. M. (2020). Relationship between cognitive reserve and cognitive impairment in autonomous and institutionalized older adults. International Journal of Environmental Research and Public Health, 17(16). https://doi.org/10.3390/ijerph17165777

Wood, S. N. (2017). Generalized additive models: An introduction with R, second edition. In Generalized Additive Models: An Introduction with R, Second Edition. https://doi.org/10.1201/9781315370279

Yeudall, L. T., Fromm, D., Reddon, J. R., \& Stefanyk, W. O. (1986). Normative data stratified by age and sex for 12 neuropsychological tests. Journal of Clinical Psychology, 42(6). https://doi.org/10.1002/10974679(198611)42:6<918::AID-JCLP2270420617>3.0.C0;2-Y

Yu, R. L., Lee, W. J., Li, J. Y., Chang, Y. Y., Chen, C. C., Lin, J. J., ... Fuh, J. L. (2020). Evaluating Mild Cognitive Dysfunction in Patients with Parkinson's Disease in Clinical Practice in Taiwan. Scientific Reports, 10(1). https://doi.org/10.1038/s41598-020-58042-2

Zhang, J., Zhou, W., Wang, L., \& Zhang, X. (2017). Gender differences of neuropsychological profiles in cognitively normal older people without amyloid pathology. Comprehensive Psychiatry, 75. https://doi.org/10.1016/j.comppsych.2017.02.008

Zhang, M., Katzman, R., Salmon, D., Jin, H., Cai, G., Wang, Z., ... Liu, W. T. (1990). The prevalence of dementia and Alzheimer's disease in Shanghai, China: Impact of age, gender, and education. Annals of Neurology, 27(4), 428-437. https://doi.org/10.1002/ana.410270412

\section{Figures}


(a)

Age

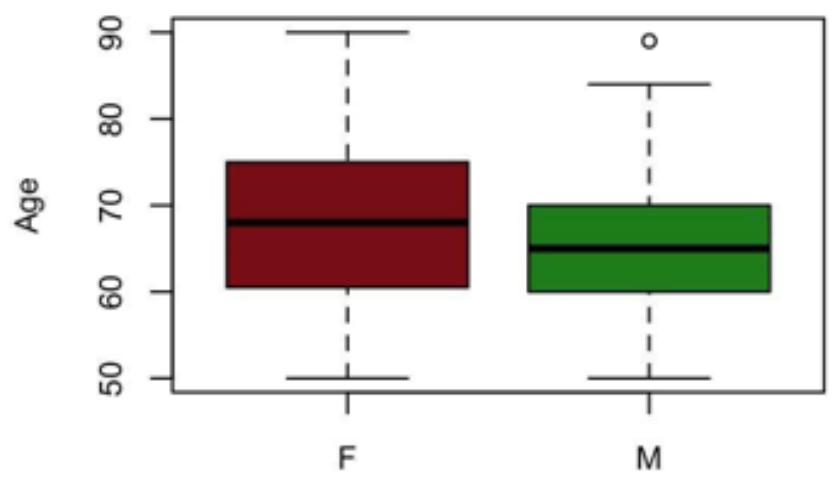

Sex

(c)

CRI

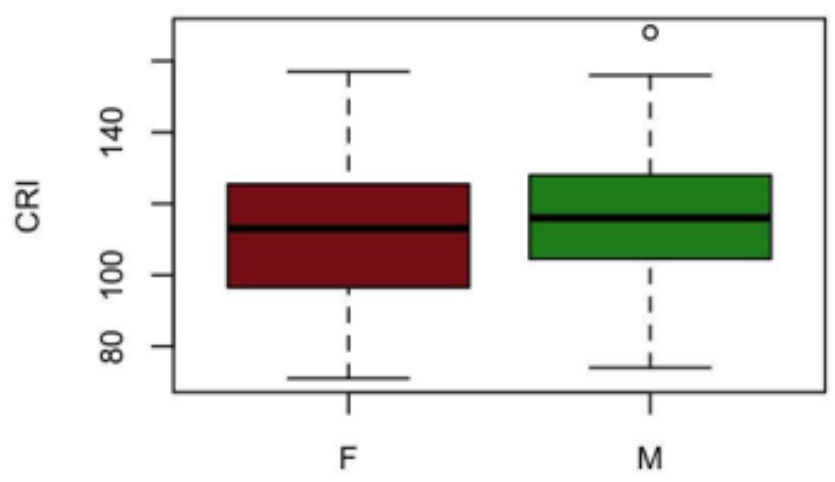

Sex (b)

Education

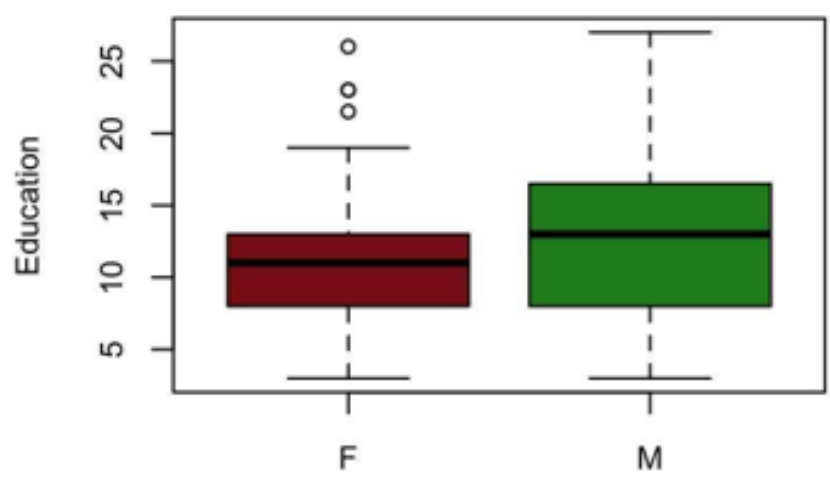

Sex

(d)

Montreal Cognitive Assessment

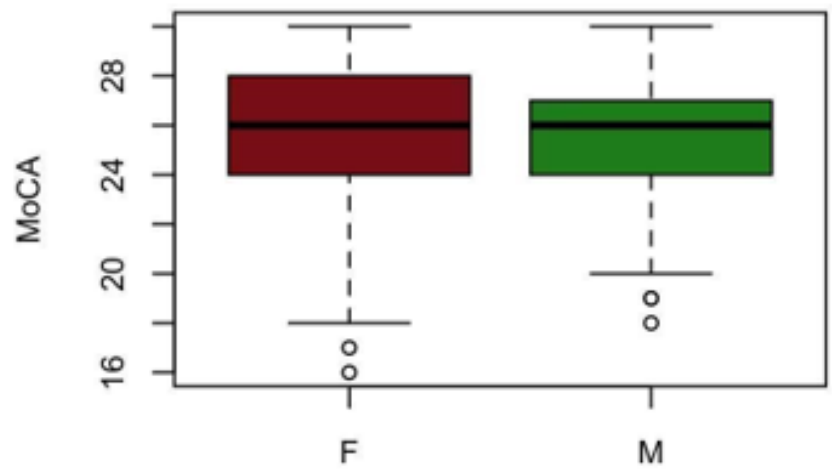

Sex

\section{Figure 1}

Boxplot of the demographic variables and MoCA raw score in female and male participants. The figure shows the boxplots for females $(F)$ and males $(M)$ in the data sample, concerning the variables: (a) Age, (b) Education, (c) Cognitive Reserve Index (i.e., CRI), and (d) raw MoCA scores. 

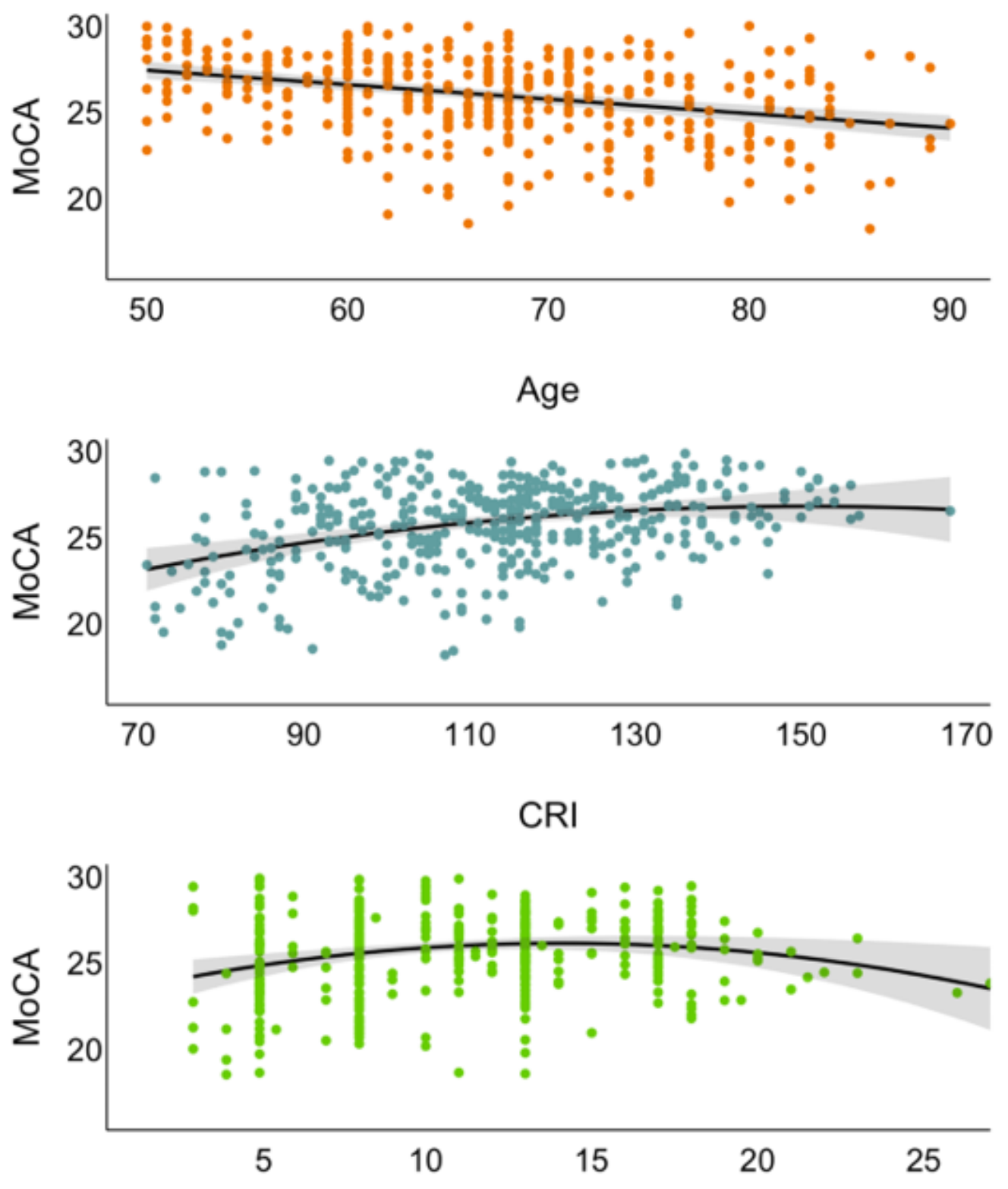

Education

\section{Figure 2}

The effect of Age, Cognitive Reserve Index and Education on MoCA scores. On the top, Age is reported on the xaxis, on the canter, the Cognitive Reserve Index (CRI) is reported on the x-axis; on the bottom, Education is reported on the $x$-axis; $y$-axes of the three figures report the scores obtained on the MoCA screening by the Italian normative sample. Based on the inspection of partial residuals, quadratic terms were included in the regression analysis. 


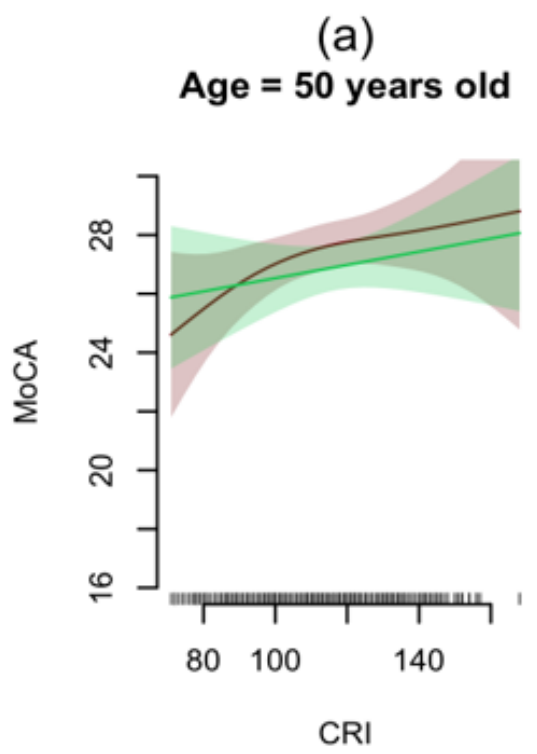

$\mathrm{F}$

(b) Age $=70$ years old

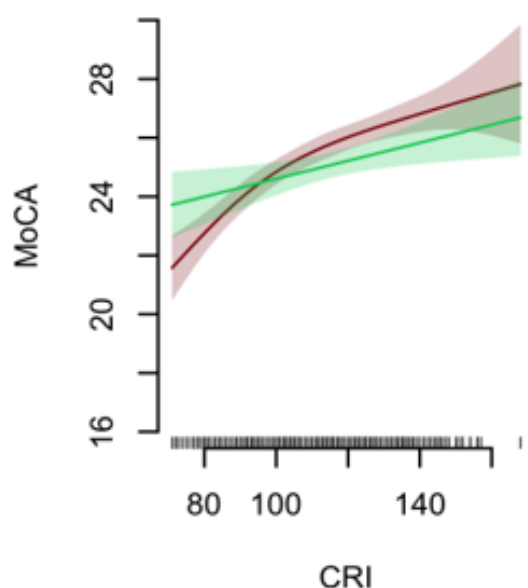

(c) Age $=90$ years old

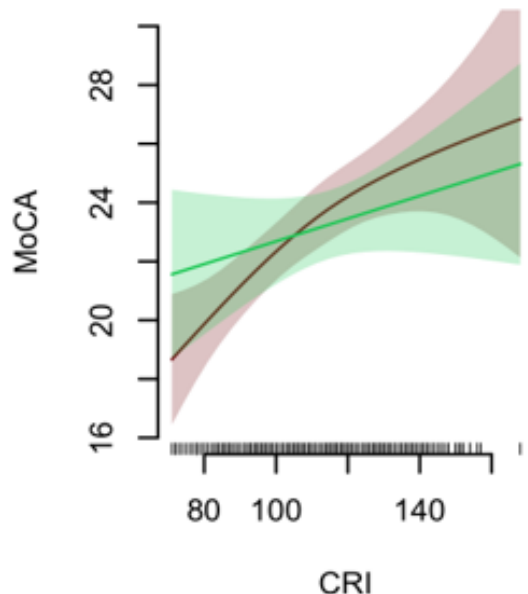

Figure 3

Effect of CRI on MoCA scores at different values of Age stages in the two Sexes. The figure reports on the yaxis the predicted MoCA scores from the sample and on the $x$-axis the CRI score of participants. The figure legend reports $F=$ females and $M=$ males. The three figures are referred to three different values of Age: a) Age $=50, \mathrm{~b})$ Age $=70$ and c) Age $=90$.

\section{Supplementary Files}

This is a list of supplementary files associated with this preprint. Click to download.

- SupplementaryMaterial.docx 